\title{
Down- and up-conversion emissions in Er-doped transparent fluorotellurite glass-ceramics
}

\author{
A. Miguel ${ }^{\mathrm{a}}$, R. Morea ${ }^{\mathrm{b}}$, J. Gonzalo ${ }^{\mathrm{b}}, \mathrm{J}_{\text {. Fernandez }}{ }^{\mathrm{a}, \mathrm{c}}$, and R. Balda ${ }^{* \mathrm{a}, \mathrm{c}}$ \\ ${ }^{a}$ Departamento de Física Aplicada I, Escuela Superior de Ingeniería, Universidad del País Vasco \\ UPV/EHU, Alda. Urquijo s/n 48013 Bilbao, Spain \\ ${ }^{\mathrm{b}}$ Laser Processing Group, Instituto de Optica, CSIC, Serrano 121, 28006, Madrid, Spain \\ ${ }^{c}$ Materials Physics Center CSIC-UPV/EHU and Donostia International Physics Center, 20080 San \\ Sebastián, Spain
}

\begin{abstract}
In this work, we report the near infrared and upconversion emissions of $\mathrm{Er}^{3+}$-doped transparent fluorotellurite glassceramics obtained by heat treatment of the precursor Er-doped $\mathrm{TeO}_{2}-\mathrm{ZnO}-\mathrm{ZnF}_{2}$ glass. Structural analysis shows that ErF 3 nanocrystals nucleated in the glass-ceramic sample are homogeneously distributed in the glass matrix with a typical size of $45 \pm 10 \mathrm{~nm}$. The comparison of the fluorescence properties of $\mathrm{Er}^{3+}$-doped precursor glass and glass-ceramic confirms the successful incorporation of the rare-earth into the nanocrystals. An enhancement of the red upconversion emission due to ${ }^{4} \mathrm{~F}_{9 / 2} \rightarrow{ }^{4} \mathrm{I}_{15 / 2}$ transition together with weak emission bands due to transitions from ${ }^{2} \mathrm{H}_{9 / 2},{ }^{4} \mathrm{~F}_{3 / 25 / 2}$, and ${ }^{4} \mathrm{~F}_{7 / 2}$ levels to the ground state are observed under excitation at $801 \mathrm{~nm}$ in the glass-ceramic sample. The temporal evolution of the red emission together with the excitation upconversion spectrum suggest that energy transfer processes are responsible for the enhancement of the red emission.
\end{abstract}

Keywords: Rare-earth-doped materials; Nanocrystalline glass-ceramics; Spectroscopy, time-resolved; Laser materials.

\section{INTRODUCTION}

Rare-earth-doped oxyfluoride glass-ceramics have attracted much attention because they combine the low effective phonon energies of fluoride crystals with the high chemical durability and thermal stability of oxide glasses. Among different oxide glasses, tellurite glasses combine good mechanical stability, chemical durability, and high linear and nonlinear refractive indices, with a wide transmission window (typically $0.4-6 \mu \mathrm{m}$ ), which make them promising materials for photonic applications [1].

In 1995, Shioya et al. [2] reported the fabrication of transparent glass-ceramics of the system $\mathrm{TeO}_{2}-\mathrm{Nb}_{2} \mathrm{O}_{5}-\mathrm{K}_{2} \mathrm{O}$ with better optical and dielectric properties than those of the precursor glass and discovered that the crystallized glasses present second-harmonic generation [2,3]. It was also found that this glass-ceramic (GC) doped with $\mathrm{Er}^{3+}$ ions showed higher green upconversion emission than the corresponding glass [4,5]. More recently, Jlassi et al. reported the effect of heat treatment on the structural and optical properties of tellurite glasses of composition $75 \mathrm{TeO}_{2}-20 \mathrm{ZnO}-4 \mathrm{Na}_{2} \mathrm{CO}_{3}-$ $1 \mathrm{Er}_{2} \mathrm{O}_{3}$ and they found an enhancement of the infrared emission at $1.5 \mu \mathrm{m}[6]$.

Mixed fluorotellurite glasses which combine the low phonon energies of fluorides with the high chemical durability and thermal stability of tellurites can reduce the $\mathrm{OH}$ content which has a great influence in the quenching processes of the radiative emission of excited levels of rare earth ions, which increases fluorescence lifetimes [7,8]. The transformation, by the adequated heat treatment, of flurotellurite glasses into glass-ceramics in which the rare-earth (RE) ions are incorporated in the crystalline phase can increase the maximum cross-sections of the RE ions and the emission efficiency. However, up to now, there are only a few works dealing with $\mathrm{Er}^{3+}$-doped fluorotellurite glass ceramics $[9,10]$.

*rolindes.balda@ehu.es; phone 3494601 404268; fax 34946014178

Optical Components and Materials XII, edited by Shibin Jiang,

Michel J. F. Digonnet, Proc. of SPIE Vol. 9359, 93590X · (C) 2015

SPIE $\cdot$ CCC code: $0277-786 \mathrm{X} / 15 / \$ 18 \cdot$ doi: $10.1117 / 12.2075584$ 
In this paper, we report the near infrared and upconversion emissions of $\mathrm{Er}^{3+}$-doped transparent fluorotellurite glassceramics obtained by the heat treatment of the $\mathrm{Er}^{3+}$-doped $74.6 \mathrm{TeO}_{2}-8.8 \mathrm{ZnO}-16.6 \mathrm{ZnF}_{2}$ glass. The effect of the heat treatment on absorption spectra, near infrared luminescence, and upconversion emission is investigated by using steadystate and time-resolved laser spectroscopy. The comparison of the fluorescence properties of $\mathrm{Er}^{3+}$-doped precursor glass and glass-ceramic confirms the successful incorporation of the rare-earth into the nanocrystals. Differential Thermal Analysis (DTA), Transmission Electron Microscopy (TEM), and Energy Dispersive X-ray spectroscopy (EDX) have been performed to characterize the thermal behavior and structure of the glass-ceramic. The structural analysis shows that the $\mathrm{ErF}_{3}$ nanocrystals nucleated in the glass-ceramic sample are homogeneously distributed in the glass matrix with a typical size of $45 \pm 10 \mathrm{~nm}$.

\section{EXPERIMENTAL}

Precursor fluorotellurite glass with a nominal composition of $74.6 \mathrm{TeO}_{2}-8.8 \mathrm{ZnO}-16.6 \mathrm{ZnF}_{2} \mathrm{~mol} \%$ doped with $1 \mathrm{wt} \%$ of $\mathrm{ErF}_{3}$, which corresponds to $1.4 \cdot 10^{20}$ ions $/ \mathrm{cm}^{3}$, was prepared by the conventional melt-quenching technique. Prior to the glass melting, high purity ( $>99.99 \%)$ oxides and fluorides $\left(\mathrm{TeO}_{2}, \mathrm{ZnO}, \mathrm{ZnF}_{2}\right.$ and $\left.\mathrm{ErF}_{3}\right)$ were well mixed in an agate ball mill. Then, the batch was melted in covered platinum crucible using an electrical vertical furnace at $850{ }^{\circ} \mathrm{C}$ for 20 minutes. The glass melt was homogenized by using an electrical platinum stirrer and finally, was poured onto a preheated brass mould. The obtained glass block $\left(\approx 2 \mathrm{~cm}^{3}\right.$ size $)$ was immediately annealed for $10 \mathrm{~min}$ at $320^{\circ} \mathrm{C}$ and then cooled down to room temperature (cooling rate $2^{\circ} \mathrm{C} \cdot \mathrm{min}^{-1}$ ).

Differential Thermal Analysis (DTA) of the glass samples was performed to determine the glass transition $\left(T_{g}\right)$, crystallization $\left(T_{c}\right)$ and melting $\left(T_{m}\right)$ temperatures. DTA experiments were performed in a TA Instruments SDT Q600 apparatus in $\mathrm{N}_{2}$ gas flow $(100 \mathrm{ml} / \mathrm{min})$ at a heating rate of $10{ }^{\circ} \mathrm{C} \cdot \mathrm{min}^{-1}$ in the $200-850{ }^{\circ} \mathrm{C}$ temperature range, using a constant amount $(50 \mathrm{mg})$ of grinded glass samples and high purity alumina crucibles as reference. The characteristic temperatures of the glass samples were found to be reproducible within $\pm 3{ }^{\circ} \mathrm{C}$. A fraction of the precursor glass underwent a two step heat treatment in order to nucleate a glass-ceramic phase.

The microstructure of the samples and chemical composition of the crystallites have been analyzed by Transmission Electron Microscopy (TEM) and Energy Dispersive X-ray spectroscopy (EDX). TEM samples where prepared by Focused Ion Beam, whereas EDX samples where prepared by the replica method using a carbon layer [11].

Absorption spectra were measured using a Cary 5 spectrophotometer. The steady-state emission measurements were made with an argon laser and a Ti:sapphire ring laser in the 770-920 nm spectral range as exciting light. The fluorescence was analyzed with a 0.25 monochromator, and the signal was detected with Hamamatsu R928 and H10330A-75 photomultipliers and finally amplified by a standard lock-in technique.

Lifetime measurements were obtained by exciting the samples with a dye laser pumped by a pulsed nitrogen laser and a Ti:sapphire laser pumped by a pulsed frequency doubled Nd:YAG laser ( 9 ns pulse width), and detecting the emission with Hamamatsu R928 and H10330A-75 photomultipliers. Data were processed by a Tektronix oscilloscope.

\section{RESULTS AND DISCUSSION}

\subsection{Structural properties}

Figure 1 shows the DTA curve of the precursor fluorotellurite glass. The glass transition temperature is $T_{g} \approx 293{ }^{\circ} \mathrm{C}$, while the crystallization peak occurs at $T_{c} \approx 390{ }^{\circ} \mathrm{C}$ and melting of two different phases are observed at $T_{m} \approx 505^{\circ} \mathrm{C}$ and $614{ }^{\circ} \mathrm{C}$ respectively. The glass stability range $\left(T_{c}-T_{g}\right)$ is close to $100{ }^{\circ} \mathrm{C}$. According to these results, the precursor glass sample was heated by using two steps: the first treatment was done at a temperature close to $T_{g}$ for 10 hours, that was immediately followed by a 3 hours treatment at a temperature slightly below that of the onset of crystallization.

TEM analysis clearly demonstrates the formation of nanocrystals (NCs) in the GC sample as it is shown in Fig. 2a. They present a dendritic structure with typical sizes of $45 \pm 10 \mathrm{~nm}$ with clear lattice fringes. EDX analysis of GC nanocrystals (Fig. 2b) shows intense peaks corresponding to $\mathrm{F}$ and $\mathrm{Er}$ in addition to those associated to the C layer of the replica and the $\mathrm{Cu}$ grid $(\mathrm{C}, \mathrm{O}$, and $\mathrm{Cu})$. Peaks related to $\mathrm{Zn}$ or Te are not observed, which suggests that NCs are formed by $\mathrm{ErF}_{3}$. Figure 3 shows a digital Fast Fourier Transform (FFT) of the NC image shown in Fig. 2a. The pattern shows intense spots that can be indexed according the crystalline structure of $\mathrm{ErF}_{3}$. This, along with the EDX results, supports that nanocrystals are made of $\mathrm{ErF}_{3}$. 


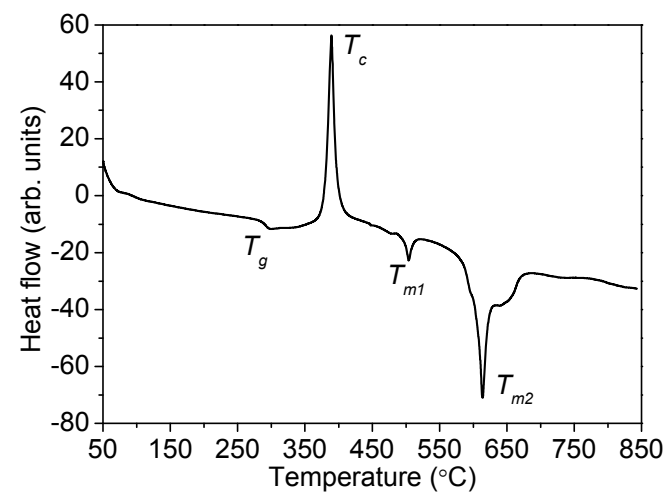

Fig. 1. Differential Thermal Analysis curve of the precursor glass.
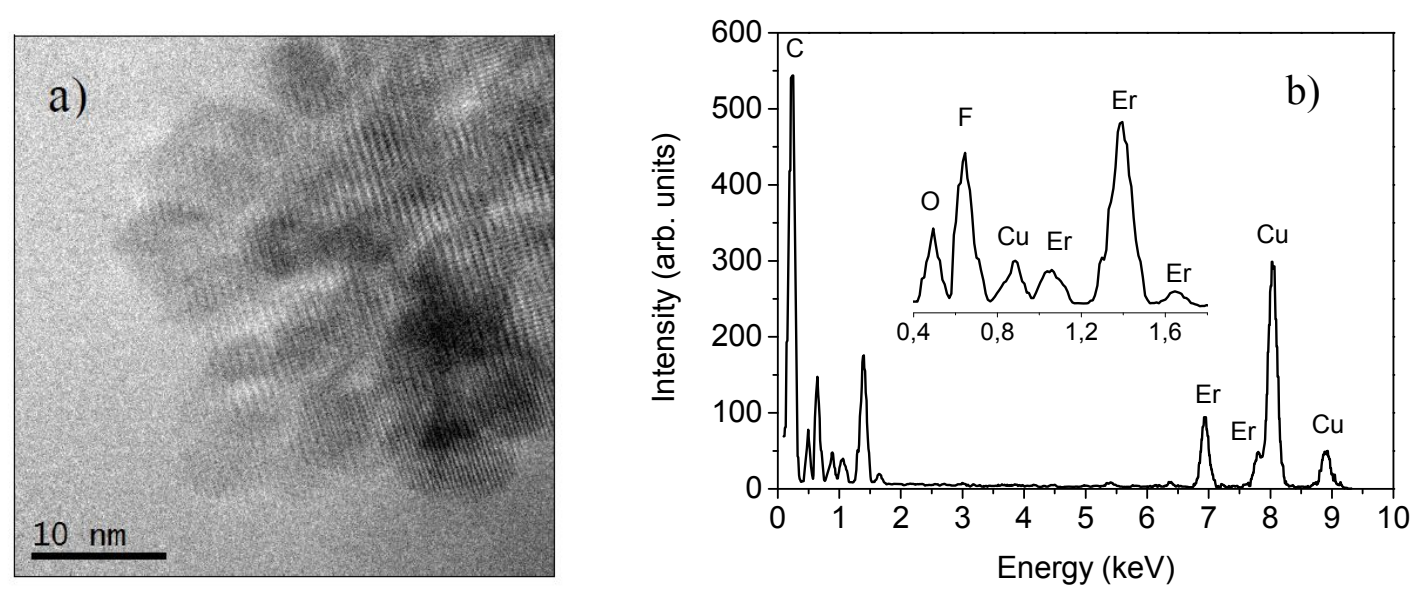

Fig. 2. (a) HRTEM image of the GC sample. (b) EDX spectrum of the nanocrystals observed on the GC sample.

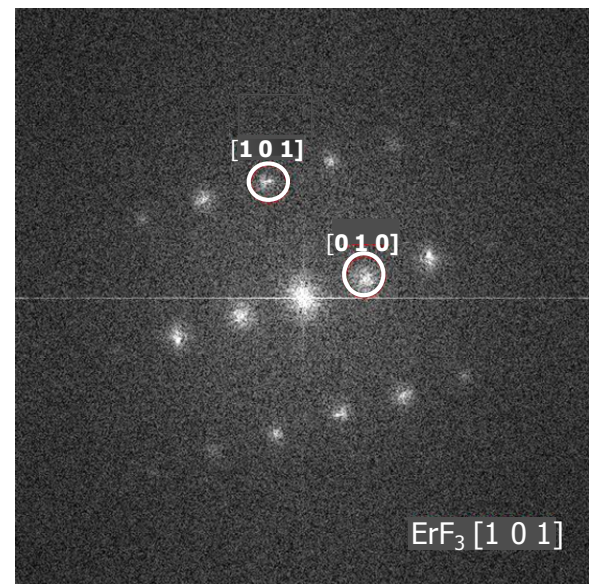

Fig. 3. Fast Fourier Transform (FFT) image indexed according to the $\mathrm{ErF}_{3}$ structure. 


\subsection{Absorption and emission properties}

The influence of the heat treatment on the spectroscopic properties of $\mathrm{Er}^{3+}$ ions in glass-ceramic sample has been studied by using absorption and steady-state and time-resolved laser spectroscopy. The absorption spectra of the glass and glass ceramic samples are displayed in Fig. 4 . The absorption bands are assigned to the transitions from the ${ }^{4} \mathrm{I}_{15 / 2}$ ground state to the excited states of $\mathrm{Er}^{3+}$ ions. As can be seen, after the heat treatment, the absorption edge is shifted to longer wavelengths in the GC sample due to the scattering of short wavelength light by the NCs present in the GC sample. Moreover, the intensity of the hypersensitive transition ${ }^{4} \mathrm{I}_{15 / 2} \rightarrow{ }^{2} \mathrm{H}_{11 / 2}$ is strongly reduced in the GC sample which indicates that the ligand field around $\mathrm{Er}^{3+}$ ions has changed as a consequence of the heat treatment. The strength of the hypersensitive transitions is greatly affected by the environment of rare earth ions. Ligand polarizability as well as an asymmetric surrounding environment increases the intensity of hypersensitive transitions of rare earth ions [10]. Another evidence of the incorporation of $\mathrm{Er}^{3+}$ ions in the nanocrystals is the splitting of the inhomogeneously broadened absorption bands in the absorption spectrum of the GC sample. As an example, the inset in Fig. 4 shows a detail of the ${ }^{4} \mathrm{I}_{15 / 2} \rightarrow{ }^{4} \mathrm{I}_{13 / 2}$ absorption band for the glass and glass-ceramic samples.

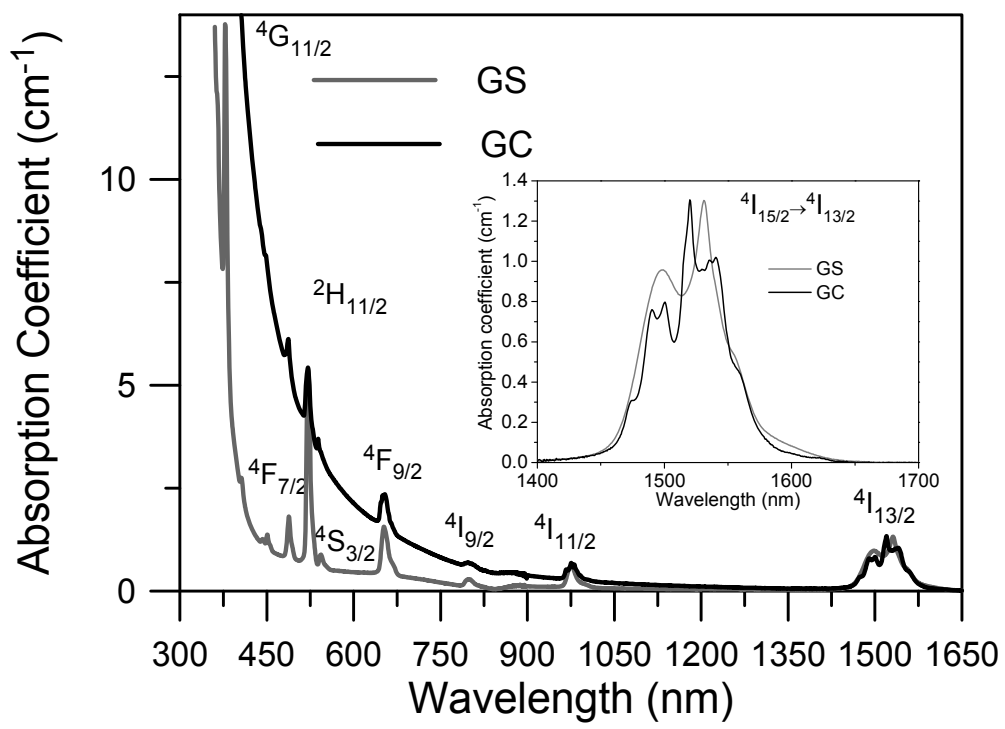

Fig. 4. Room temperature absorption coefficient for precursor glass and glass-ceramic samples. The inset shows the detail of the ${ }^{4} \mathrm{I}_{15 / 2} \rightarrow{ }^{4} \mathrm{I}_{13 / 2}$ absorption bands.

Near infrared emission spectra were obtained at room temperature by exciting at $801 \mathrm{~nm}$ in the ${ }^{4} \mathrm{I}_{9 / 2}$ level. After excitation of this level, the next lower levels are populated by multiphonon relaxation. Two emission bands were observed at around 980 and $1530 \mathrm{~nm}$, which correspond to transitions from ${ }^{4} \mathrm{I}_{11 / 2}$ and ${ }^{4} \mathrm{I}_{13 / 2}$ levels to the ground state respectively. Figure 5 shows the emission spectra for both samples. The emission band corresponding to the ${ }^{4} \mathrm{I}_{13 / 2} \rightarrow{ }^{4} \mathrm{I}_{15 / 2}$ transition of the GC sample shows a more resolved structure with peaks at 1488, 1499, 1520, 1540, and $1555 \mathrm{~nm}$. Moreover, the effective bandwidth, defined as $\Delta \lambda_{\text {eff }}=\int \frac{I(\lambda) d \lambda}{I_{\max }}$, is reduced from $73.4 \mathrm{~nm}$ in the GS to $64 \mathrm{~nm}$ in the GC sample probably due to the reduction of inhomogeneous broadening.

To obtain a reliable estimation of the stimulated emission cross-section of the ${ }^{4} \mathrm{I}_{13 / 2} \rightarrow{ }^{4} \mathrm{I}_{15 / 2}$ transition in the GC sample, the fluorescence profile was obtained from the absorption spectrum by using the McCumber approach [12], which relates the absorption and emission cross-sections by,

$$
\sigma_{e m}(v)=\sigma_{a}(v) \exp \left[\frac{(\varepsilon-h v)}{K T}\right]
$$


where $\sigma_{\mathrm{a}}$ and $\sigma_{\mathrm{em}}$ are the absorption and emission cross-sections respectively, $v$ is the photon frequency, $\varepsilon$ is the net free energy required to excite one $\mathrm{Er}^{3+}$ ion from the ${ }^{4} \mathrm{I}_{15 / 2}$ to the ${ }^{4} \mathrm{I}_{13 / 2}$ state at temperature $\mathrm{T}, \mathrm{h}$ is the Planck constant, and $\mathrm{K}$ is the Boltzmann constant. The absorption cross-section has been experimentally obtained and $\varepsilon$ can be determined by using the simplified procedure provided in reference 13. As an example, Fig. 6 shows the absorption and emission crosssections obtained for the GC sample together with the normalized measured emission spectrum. As can be seen the emission profile is similar. The stimulated emission cross-section has a value of $8.9 \cdot 10^{-21} \mathrm{~cm}^{2}$, similar to the one found in the glass sample $\left(8.8 \cdot 10^{-21} \mathrm{~cm}^{2}\right)$ [8] and higher than those found in other fluorotellurite glass-ceramics [6].

The excitation spectra of the ${ }^{4} \mathrm{I}_{15 / 2} \rightarrow{ }^{4} \mathrm{I}_{13 / 2}$ transition obtained by collecting the luminescence at $1530 \mathrm{~nm}$ for the glassceramic sample also suggest that $\mathrm{Er}^{3+}$ ions are incorporated in a crystalline phase in this glass-ceramic. As can be seen in Fig. 7, the spectrum corresponding to the GC sample shows well defined peaks not observed in the excitation spectrum of the glass sample.

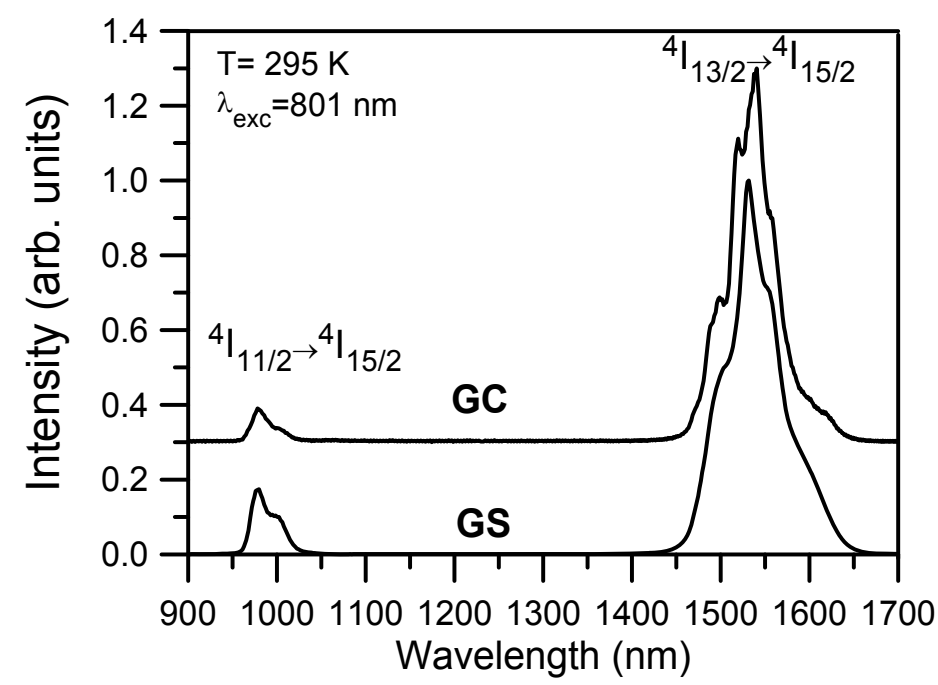

Fig. 5. Near infrared emission spectra obtained under excitation at $801 \mathrm{~nm}$ in the glass and glass-ceramic samples.

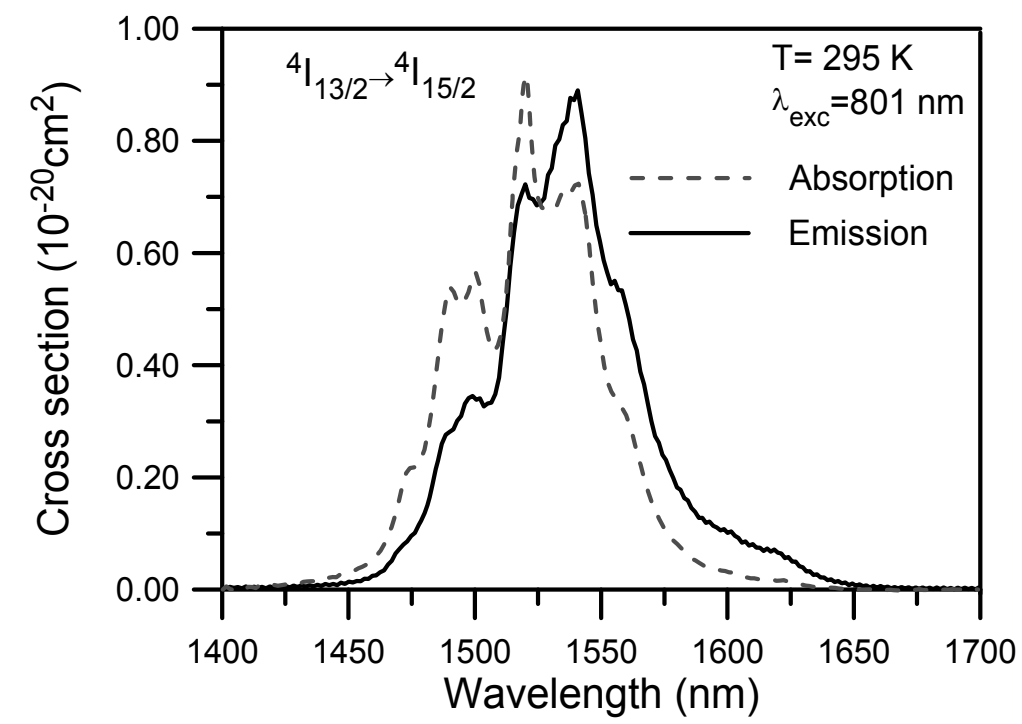

Fig. 6. Absorption and emission cross-sections of the ${ }^{4} \mathrm{I}_{13 / 2} \leftrightarrow{ }^{4} \mathrm{I}_{15 / 2}$ transitions for the GC sample. 


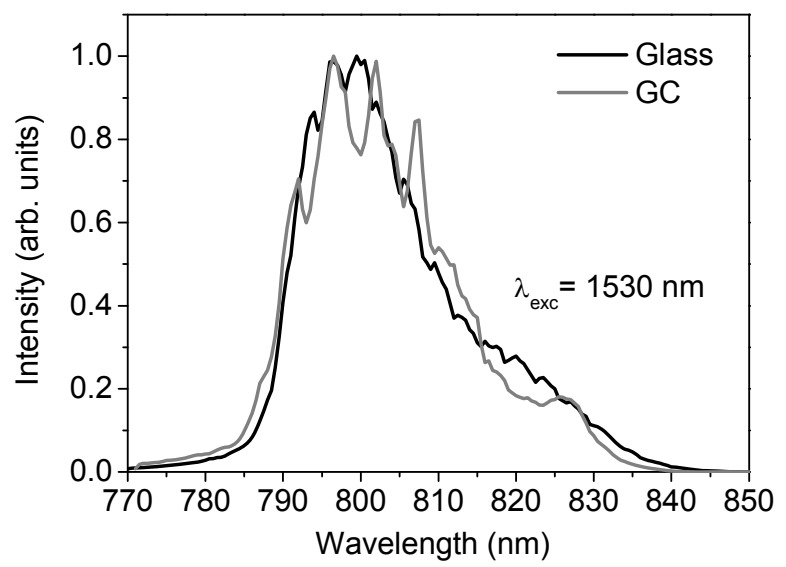

Fig. 7. Excitation spectra of the ${ }^{4} \mathrm{I}_{15 / 2} \rightarrow{ }^{4} \mathrm{I}_{9 / 2}$ transition obtained by collecting the luminescence at $1530 \mathrm{~nm}$ in the glass and glass-ceramic samples.

The decay curves from ${ }^{4} \mathrm{I}_{13 / 2}$ level for both samples have been obtained by pumping level ${ }^{4} \mathrm{I}_{9 / 2}$ at $801 \mathrm{~nm}$. In both samples, an initial rise time due to the population from the higher ${ }^{4} \mathrm{I}_{11 / 2}$ level is observed. Figure 8 shows the experimental decay curves for GC and GS samples. The decay of the glass sample can be described by a single exponential function with a lifetime of $3.6 \mathrm{~ms}$. However, the experimental decay of the GC sample can not be described by a single exponential function due to the crystallization process. In this case, the decay is well described by a double exponential function with lifetimes of 1.2 and $3.1 \mathrm{~ms}$ which suggest different contributions from different kinds of environment around $\mathrm{Er}^{3+}$ ions. In this GC, one part of $\mathrm{Er}^{3+}$ ions remains in a glass environment while the other one is forming NCs. The reduction in lifetimes after heat treatment has been previously reported [14] and attributed to the segregation of the rare-earth ions into the crystalline phase which reduces $\mathrm{Er}^{3+}-\mathrm{Er}^{3+}$ distances. Shorter distances between $\mathrm{Er}^{3+}$ ions favour dipole-dipole energy transfer between them, which increases non-radiative rates and reduces the lifetime of level ${ }^{4} \mathrm{I}_{13 / 2}$. A similar behavior is observed for the lifetime value of the ${ }^{4} \mathrm{I}_{11 / 2}$ level which is reduced from $420 \mu$ s in the glass sample to $220 \mu$ s in GC sample.

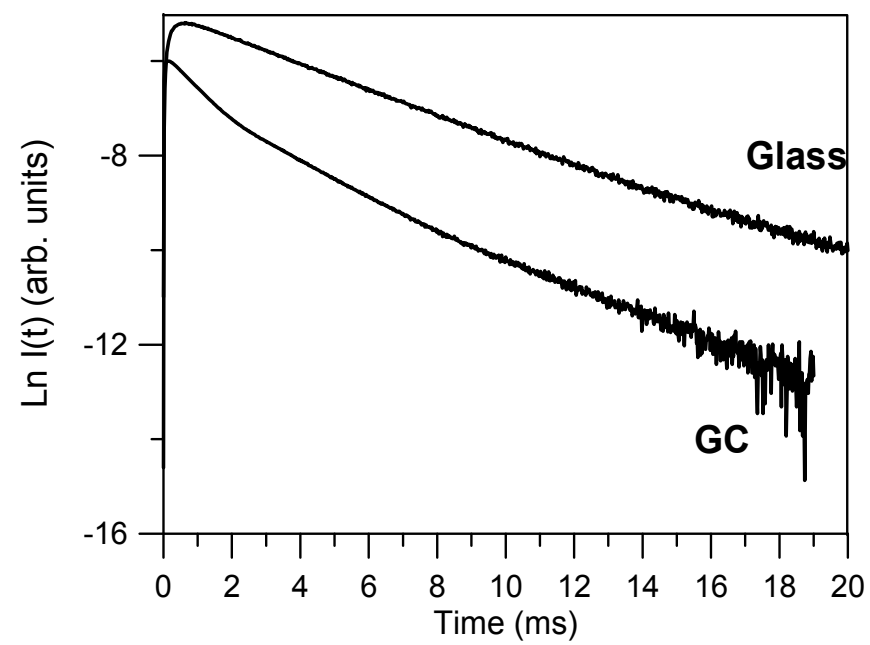

Fig. 8. Semilogarithmic plot of the fluorescence decays of the ${ }^{4} \mathrm{I}_{13 / 2}$ level for precursor glass and glass-ceramic samples obtained after excitation at $801 \mathrm{~nm}$. 


\subsection{Direct and upconverted visible emissions}

The visible emission in the 500-700 $\mathrm{nm}$ range were obtained under $488 \mathrm{~nm}$ excitation in the ${ }^{4} \mathrm{~F}_{7 / 2}$ level. After excitation of this level, the next lower levels are populated by multiphonon relaxation. Figure 9(a) shows the emission spectra for both samples. As can be seen, the main emission corresponds to the green one associated to the $\left({ }^{2} \mathrm{H}_{11 / 2},{ }^{4} \mathrm{~S}_{3 / 2}\right) \rightarrow{ }^{4} \mathrm{I}_{15 / 2}$ thermalized transitions. The weak red emission from level ${ }^{4} \mathrm{~F}_{9 / 2}$ is due to its population from level ${ }^{4} \mathrm{~S}_{3 / 2}$ through multiphonon relaxation.

Visible upconversion emission has also been observed for both glass and GC samples at room temperature under continuous wave (cw) and pulsed laser excitation in resonance with the ${ }^{4} \mathrm{I}_{9 / 2}$ level. The upconverted emission spectra obtained under $\mathrm{cw}$ excitation were measured by using a Ti-sapphire ring laser. Cut-off filters were used to remove the pumping radiation. As an example Fig. 9(b) shows the room temperature upconverted emission spectra of $\mathrm{Er}^{3+}$ in both samples obtained under excitation at $801 \mathrm{~nm}$. The observed emissions correspond to transitions ${ }^{2} \mathrm{H}_{11 / 2} \rightarrow{ }^{4} \mathrm{I}_{15 / 2}$, ${ }^{4} \mathrm{~S}_{3 / 2} \rightarrow{ }^{4} \mathrm{I}_{15 / 2}$, and ${ }^{4} \mathrm{~F}_{9 / 2} \rightarrow{ }^{4} \mathrm{I}_{15 / 2}$. The ${ }^{2} \mathrm{H}_{11 / 2} \rightarrow{ }^{4} \mathrm{I}_{15 / 2}$ emission can be observed at room temperature because the ${ }^{2} \mathrm{H}_{11 / 2}$ level is populated from ${ }^{4} \mathrm{~S}_{3 / 2}$ via fast thermal equilibrium between levels. As can be observed the most intense emission corresponds to the green emission from level ${ }^{4} \mathrm{~S}_{3 / 2}$. The emission bands are better resolved in the GC spectrum in agreement with the incorporation of $\mathrm{Er}^{3+}$ ions in the crystalline phase. In addition, very weak bands centered at around 408,45 , and $488 \mathrm{~nm}$ can be observed in the spectrum of the GC sample, corresponding to the ${ }^{2} \mathrm{H}_{9 / 2} \rightarrow{ }^{4} \mathrm{I}_{15 / 2},\left({ }^{4} \mathrm{~F}_{3 / 2}\right.$, $\left.{ }^{4} \mathrm{~F}_{5 / 2}\right) \rightarrow{ }^{4} \mathrm{I}_{15 / 2}$, and ${ }^{4} \mathrm{~F}_{7 / 2} \rightarrow{ }^{4} \mathrm{I}_{15 / 2}$ transitions, which do not appear in the upconversion emission of the glass sample. Moreover, the red emission of GC sample increases significantly compared to that of the glass sample. In fact, the ratio between the red and green emission intensities is 0.075 and 0.93 for the glass and GC samples, respectively. This increase of the red emission, not observed in the spectra obtained by exciting at $488 \mathrm{~nm}$, indicates that after NIR excitation, level ${ }^{4} \mathrm{~F}_{9 / 2}$ is populated by energy transfer processes in addition to multiphonon relaxation from level ${ }^{4} \mathrm{~S}_{3 / 2}$. This behavior could be associated to a higher concentration of $\mathrm{Er}^{3+}$ ions in the nanocrystals, which reduces the $\mathrm{Er}^{3+}-\mathrm{Er}^{3+}$ distances and increases the probability of energy transfer processes $[15,16]$.
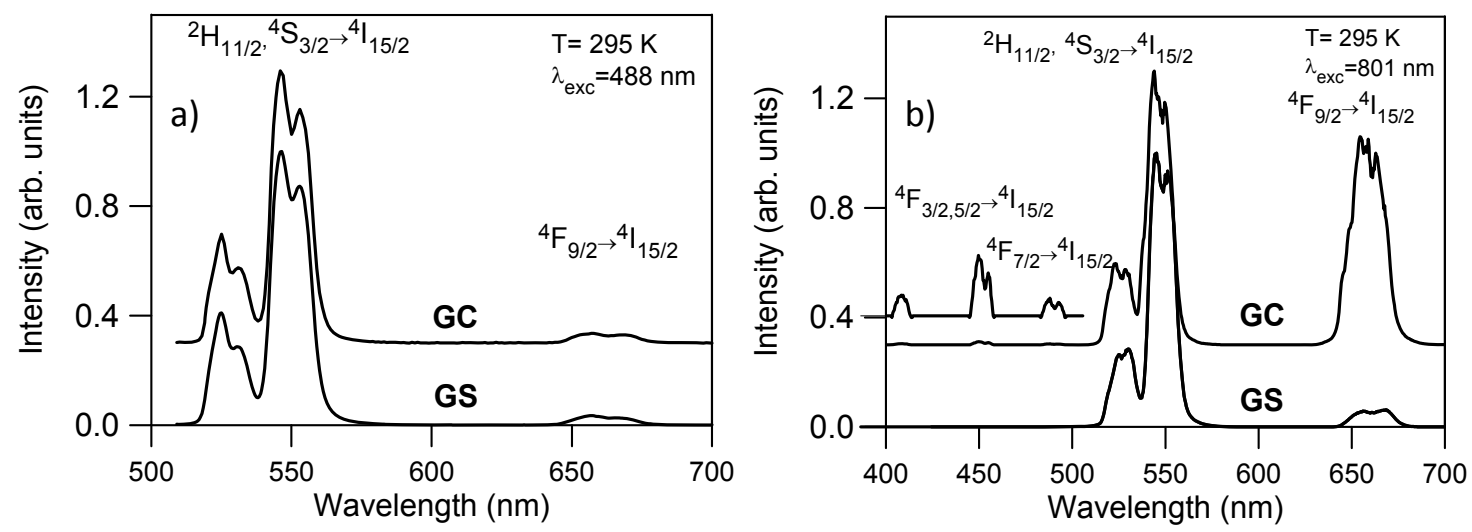

Fig. 9. Visible emission obtained a) under $488 \mathrm{~nm}$ and b) under $801 \mathrm{~nm}$ excitation for the glass and glass-ceramic samples.

To confirm that ETU processes are responsible for the red emission, lifetime measurements have been performed. As it is well known, the time evolution of the upconversion luminescence after an excitation pulse provides a useful tool in discerning which the operative mechanism is. The radiative ESA process occurs during the excitation pulse and leads to an immediate decay of the upconversion luminescence after excitation. Upconversion by energy transfer leads to a timedependent emission that shows a rise of the upconverted population after the laser pulse, followed by a decay of the population, with a lifetime longer than the one after direct excitation. The rise and decay times are determined by both the intermediate and the upper excited state lifetimes. This distinction is possible when the pump pulse width is much shorter than the time constant of the relevant energy transfer step.

As we have seen in Fig. 9, in the case of the upconverted emission, after excitation at $801 \mathrm{~nm}$, there is an increase in the red emission intensity relative to the green one in the GC sample. In addition, the experimental decays for the red emission obtained after NIR excitation, show a lengthening of the ${ }^{4} \mathrm{~F}_{9 / 2}$ lifetime compared to the one obtained under 488 
$\mathrm{nm}$. As an example, the time evolution of the red emission obtained under excitation at $801 \mathrm{~nm}$ and $488 \mathrm{~nm}$ for the GC sample is shown in Fig. 10. In both cases, the decays can be described by two components. The fast one ( $\sim 21 \mu \mathrm{s})$ is similar for both excitation wavelengths whereas the lifetime of the slow component increases from $89 \mu \mathrm{s}$ to $183 \mu \mathrm{s}$ when the excitation wavelength changes from $488 \mathrm{~nm}$ to $801 \mathrm{~nm}$. Moreover, there is an initial rise time of about $15 \mu \mathrm{s}$. The presence of a rise time together with the lengthening of the slow component of the decay supports the hypothesis that ETU processes are populating level ${ }^{4} \mathrm{~F}_{9 / 2}$. According to the energy level diagram of $\mathrm{Er}^{3+}$ ions in the GC sample (Fig. 11), there are different ETU processes to populate the ${ }^{4} \mathrm{~F}_{9 / 2}$ level. This level can be populated via $\left({ }^{4} \mathrm{I}_{9 / 2} \rightarrow{ }^{4} \mathrm{I}_{13 / 2}\right)$ and $\left({ }^{4} \mathrm{I}_{11 / 2} \rightarrow{ }^{4} \mathrm{~F}_{9 / 2}\right)$ transitions and/or $\left({ }^{4} \mathrm{I}_{11 / 2} \rightarrow{ }^{4} \mathrm{I}_{15 / 2}\right)$ and $\left({ }^{4} \mathrm{I}_{13 / 2} \rightarrow{ }^{4} \mathrm{~F}_{9 / 2}\right)$. There exists another possible process for populating level ${ }^{4} \mathrm{~F}_{9 / 2}$ in which two $\mathrm{Er}^{3+}$ ions interact, one of them in level ${ }^{4} \mathrm{I}_{11 / 2}$ and the other one in level ${ }^{4} \mathrm{~F}_{7 / 2}$, going both to level ${ }^{4} \mathrm{~F}_{9 / 2}$. By considering that the lifetime of a higher-energy level excited by ETU reflects those of the intermediate levels from which upward excitation occurs, and that the long component of the decay of the red emission after excitation at $801 \mathrm{~nm}$ is very close to the lifetime of level ${ }^{4} \mathrm{I}_{11 / 2}$, the $\left({ }^{4} \mathrm{I}_{9 / 2} \rightarrow{ }^{4} \mathrm{I}_{13 / 2}\right) ;\left({ }^{4} \mathrm{I}_{11 / 2} \rightarrow{ }^{4} \mathrm{~F}_{9 / 2}\right)$ and $\left({ }^{4} \mathrm{~F}_{7 / 2} \rightarrow{ }^{4} \mathrm{~F}_{9 / 2}\right) ;\left({ }^{4} \mathrm{I}_{11 / 2} \rightarrow{ }^{4} \mathrm{~F}_{9 / 2}\right)$ processes seem to be the likeliest ones to explain the population of the ${ }^{4} \mathrm{~F}_{9 / 2}$ level by ETU.

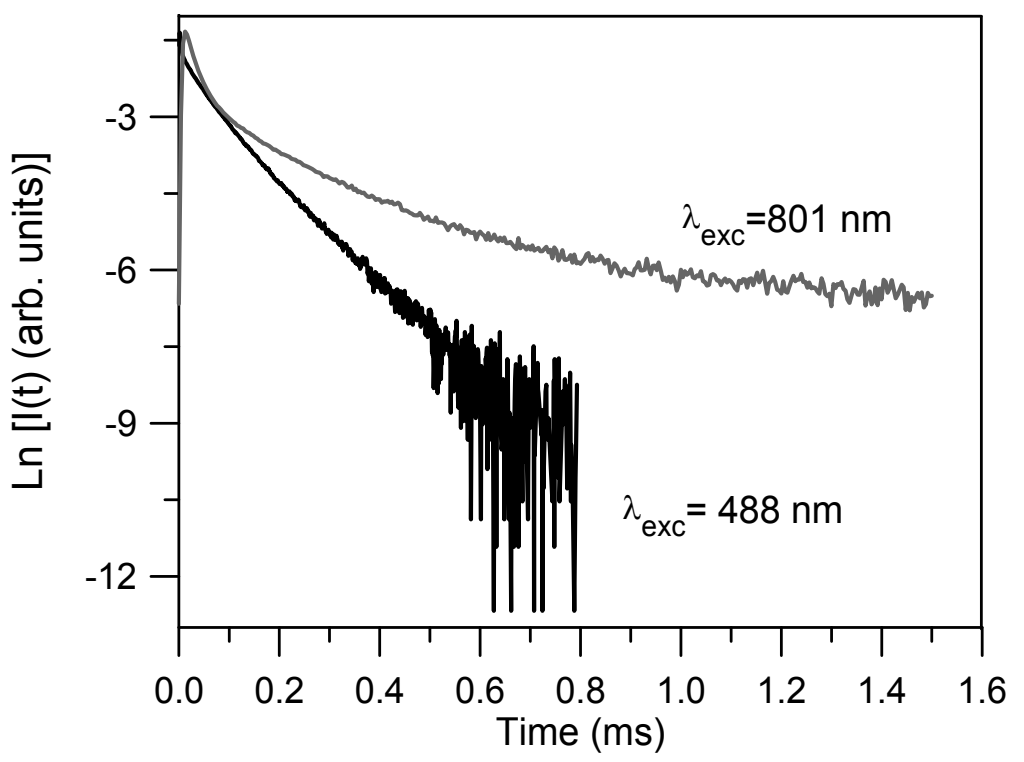

Fig. 10. Semilogarithmic plot of the experimental decay curves of the red emission under excitation at $488 \mathrm{~nm}$ and $801 \mathrm{~nm}$ for the GC sample.

In the case of the green emission, the time dependence of the upconverted luminescence from the ${ }^{4} \mathrm{~S}_{3 / 2}$ level does not show any rise time which indicates the presence of an ESA process from level ${ }^{4} \mathrm{I}_{13 / 2}$ and also a small contribution from level ${ }^{4} \mathrm{I}_{11 / 2}$. The time evolution of the decays from the ${ }^{4} \mathrm{~S}_{3 / 2}$ level obtained after an infrared excitation pulse of $9 \mathrm{~ns}$ in the GC sample can be described to a good approximation by two components: the fast one has a lifetime of $41 \mu$ s and the lifetime of the long component is about $129 \mu \mathrm{s}$, which is longer than the one obtained by direct excitation $(107 \mu \mathrm{s})$. This lengthening of the lifetime suggests that ETU processes such as $\left({ }^{4} \mathrm{I}_{11 / 2} \rightarrow{ }^{4} \mathrm{I}_{15 / 2}\right)$ and $\left({ }^{4} \mathrm{I}_{11 / 2} \rightarrow{ }^{4} \mathrm{~F}_{7 / 2}\right)$ can also be responsible for the green emission. In this process two $\mathrm{Er}^{3+}$ ions in the ${ }^{4} \mathrm{I}_{11 / 2}$ level interact and one of them goes to the ground state whereas the other one reaches the ${ }^{4} \mathrm{~F}_{7 / 2}$ level from where level ${ }^{4} \mathrm{~S}_{3 / 2}$ is populated by nonradiative relaxation. This ETU process is responsible for the long lifetime of the green emission. 


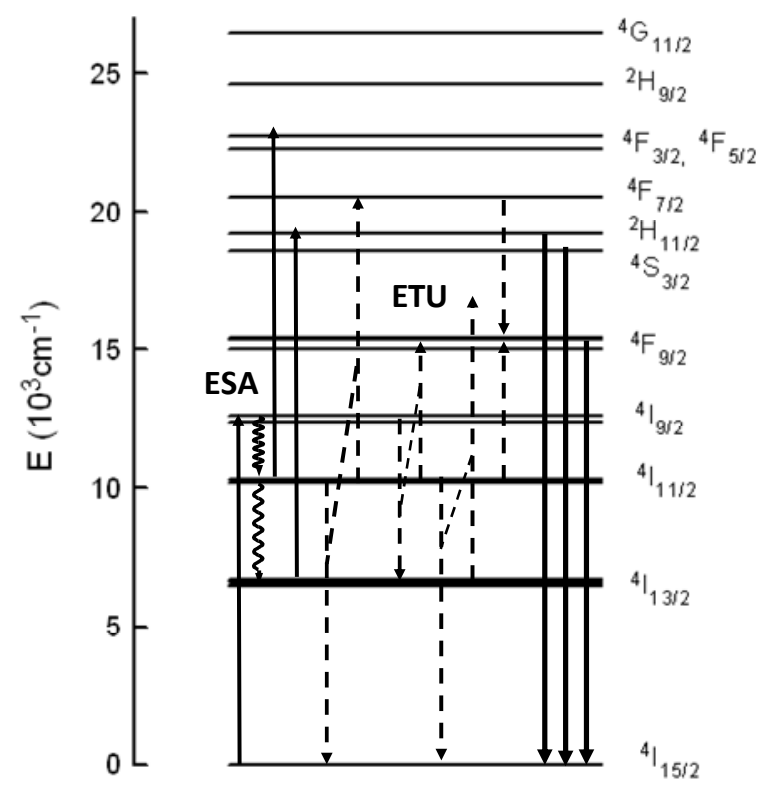

Fig. 11. Energy level diagram of $\mathrm{Er}^{3+}$ ions in the GC sample and possible upconversion mechanisms.

\section{CONCLUSIONS}

Transparent glass-ceramics have been obtained by a specific selection of precursors and customized heat treatment of an $\mathrm{Er}^{3+}$-doped fluorotellurite glass with a nominal composition of $74.6 \mathrm{TeO}_{2}-8.8 \mathrm{ZnO}-16.6 \mathrm{ZnF}_{2} \mathrm{~mol}_{0}$. Structural analysis shows that $\mathrm{ErF}_{3}$ nanocrystals nucleated in the glass-ceramics have a typical size of $45 \pm 10 \mathrm{~nm}$.

The analysis of the spectroscopic properties shows the split of the absorption and emission bands in the glass-ceramic sample. The absorption spectra shows that the intensity of hypersensitive transition ${ }^{4} \mathrm{I}_{15 / 2} \rightarrow{ }^{2} \mathrm{H}_{11 / 2}$ is strongly reduced in the GC sample compared with the glass sample, which indicates that the ligand field around $\mathrm{Er}^{3+}$ ions has changed as a consequence of the heat treatment. The ${ }^{4} \mathrm{I}_{13 / 2}$ decay in the glass-ceramic sample can be described by two single exponential functions which suggests that a fraction of $\mathrm{Er}^{3+}$ ions are forming nanocrystals while the rest remains in a glass environment. Moreover, the emission lifetime is shorter than in the glass sample probably due to the segregation of the $\mathrm{Er}^{3+}$ ions into the crystalline phase which reduces $\mathrm{Er}^{3+}-\mathrm{Er}^{3+}$ distances and increases energy transfer processes.

The presence of $\mathrm{ErF}_{3}$ nanocrystals has a strong effect in the upconverted red emission from ${ }^{4} \mathrm{~F}_{9 / 2}$ level. This emission increases significantly as compared with the green one in the GC sample. The time evolution of the upconverted red emission suggests that ETU processes are responsible for the increase of this emission in the glass-ceramic sample.

\section{ACKNOWLEDGMENTS}

We deeply acknowledge A. Ruiz-Caridad from the Laboratory of Electron Nanoscopies (LENS, University of Barcelona) and A. Tomas from the National Centre for Metallurgical Research (CENIM, CSIC) for HRTEM and EDX analysis, respectively. This work was supported by the Spanish Government MEC under Projects No. TEC2012-38901C02-01, FIS2011-27968, MAT2013-48246-C2-2-P and Basque Country Government IT-659-13. A. Miguel and R. Morea acknowledge FPI grants from the Spanish Government. 


\section{REFERENCES}

[1] R. A. H. El-Mallawany, Tellurite Glasses Handbook-Physical Properties and Data, (CRC Boca Raton, FL 2001).

[2] K. Shioya, T. Komatsu, H.G. Kim, R. Sato, K. Matusita, "Optical properties of transparent glass-ceramics in $\mathrm{K}_{2} \mathrm{O}-$ $\mathrm{Nb}_{2} \mathrm{O}_{5}-\mathrm{TeO}_{2}$," J. Non-Cryst. Solids 189, 16-24 (1995).

[3] H. G. Kim, T. Komatsu, K. Shioya, K. Matusita, K. Tanaka, K. Hirao, "Transparent tellurite-based glass-ceramics with second harmonic generation," J. Non-Cryst. Solids 208, 303-307 (1996).

[4] H. Oishi, Y. Benino, T. Komatsu, "Preparation and optical properties of transparent tellurite based glass ceramics doped by $\mathrm{Er}^{3+}$ and $\mathrm{Eu}^{3+}$, , Phys. Chem. Glasses 40, 212-218 (1999).

[5] K. Hirano, Y. Benino, T. Komatsu, "Rare earth doping into optical nonlinear nanocrystalline phase in transparent $\mathrm{TeO}_{2}$-based glass-ceramics," J. Phys. Chem. Solids 62, 2075-2082 (2001).

[6] I. Jlassi, H. Elhouichet, S. Hraiech, and M. Ferid, "Effect of heat treatment on the structural and optical properties of tellurite glasses doped erbium," J. Lumin. 132, 832-840 (2012).

[7] D. L. Sidebottom, M. A. Hruschka, B. G. Potter, and R. K. Brow, "Increased radiative lifetime of rare earth-doped zinc oxyhalide tellurite glasses," Appl. Phys. Lett. 71, 1963-1965 (1997).

[8] A. Miguel, R. Morea, J. Gonzalo, M. A. Arriandiaga, J. Fernandez, and R. Balda, "Near-infrared emission and upconversion in $\mathrm{Er}^{3+}$-doped $\mathrm{TeO}_{2}-\mathrm{ZnO}-\mathrm{ZnF}_{2}$ glasses," J. Lumin. 140, 38-44 (2013).

[9] Chunlei $\mathrm{Yu}$, Junjie Zhang, Lei Wen, Zhonghong Jiang, "New transparent $\mathrm{Er}^{3+}$-doped oxyfluoride tellurite glass ceramic with improved near infrared and up-conversion fluorescence properties," Materials Letters 61, 3644-3646 (2007).

[10] A. Miguel, R. Morea, M. A. Arriandiaga, M. Hernández, F.J . Ferrer, C. domingo, J. M. Fdez-Navarro, J. Gonzalo, J. Fernandez, R. Balda, "Structural, optical, and spectroscopic properties of $\mathrm{Er}^{3+}$-doped $\mathrm{TeO}_{2}-\mathrm{ZnO}-\mathrm{ZnF}_{2}$ glass-ceramics," J. of the European Ceramic Society 34, 3433-4116 (2014).

[11] J. Ayache, L. Beaunier, J. Boumendil, G. Ehret and D. Laub, Sample Preparation Handbook for Transmission Electron Microscopy, (Springer-Verlag, New York 2010).

[12] D. E. McCumber, "Einstein Relations Connecting Broadband Emission and Absorption Spectra," Phys. Rev. 136, A954-957 (1964).

[13] W. J. Miniscalco and R. S. Quimby, "General procedure for the analysis of $\mathrm{Er}^{3+}$ cross sections," Opt. Lett. 16, 258260 (1991).

[14] G. Dantelle, M. Mortier, G. Patriarche, and D. Vivien, "Er ${ }^{3+}$ doped $\mathrm{PbF}_{2}$ : Comparison between nanocrystals in glass-ceramics and bulk single crystals," J. Solid State Chem. 179, 1995-2003 (2006).

[15] R. Balda, S. García-Revilla, J. Fernández, V. Seznec, V. Nazabal, X. H. Zhang, J. L. Adam, M. Allix, and G. Matzen, "Upconversion luminescence of transparent $\mathrm{Er}^{3+}$-doped chalcohalide glass-ceramics," Opt. Mater. 31, 760-764 (2009).

[16] R. Balda, A. J. García-Adeva, J. Fernández, and J. M. Fdez-Navarro, "Infrared-to-visible upconversion of $\operatorname{Er}^{3+}$ ions in $\mathrm{GeO}_{2}-\mathrm{PbO}-\mathrm{Nb}_{2} \mathrm{O}_{5}$ glasses," J. Opt. Soc. Am. B 21, 744-752 (2004). 